\title{
PEMBUATAN DAN UJI ORGANOLEPTIK SELAI LEMBAR DARI KOMBINASI TOMAT (Lycopersicum esculentum Mill) DAN KULIT BUAH NAGA MERAH (Hylocereus costaricensis cortex) SEBAGAI SUPLEMEN KAYA ANTIOKSIDAN
}

\author{
Windy Septiani ${ }^{1 *}$, Reti Puji Handayani2 ${ }^{2}$, Jenta Puspariki ${ }^{3}$ \\ 1,2,3 Sekolah Tinggi Ilmu Kesehatan Holistik
}

*Korespondensi: Jl. Veteran No. 272 Ciseureuh Purwakarta, Email: windyseptiani051@gmail.com

\begin{abstract}
ABSTRAK
Latar Belakang: Di pasaran semakin banyak produk bahan pangan kaya akan senyawa antioksidan, namun kulit buah naga merah (Hylocereus costaricensis cortex) yang dianggap sebagai limbah ternyata mengandung antioksidan yang tinggi. Buah tomat (Lycopersicum esculentum Mill) memiliki aktivitas antioksidan yang sangat kuat karena mengandung likopen yang merupakan pigmen utama pada tomat.

Tujuan: Peneltian ini bertujuan untuk membuat sediaan selai lembar kombinasi dari tomat dan kulit buah naga sebagai suplemen kaya antioksidan yang mudah aman, praktis dan sehat dikomsumsi masyarakat.

Metode: Metode penelitian yang digunakan yaitu penelitian tindakan (action research) menggunakan instrumen penelitian berupa lembar uji organoleptik dan uji kesukaan. Sediaan dibuat dengan perbandingan komposisi tomat dan kulit buah naga merah masing-masing formula adalah 100 gram tomat; 100 gram kulit buah naga merah serta variasi pemanis untuk F I sebanyak 40 gram, pemanis F II sebanyak 50 gram dan pemanis pada F III sebanyak 60 gram.

Hasil: Hasil uji organoleptik pada suhu ruang $\left(15-30^{\circ} \mathrm{C}\right)$ yang telah dilakukan menunjukkan adanya perubahan pada hari ke-6 sampai hari ke-21, sedangkan pada hasil uji organoleptik pada suhu dingin $\left( \pm 4^{\circ} \mathrm{C}\right)$ tidak memiliki perubahan dari hari ke-1 sampai hari ke-21, hasil uji kesukaan selai lembar yang paling disukai responden adalah formula 2 yaitu sebanyak 86,6\%.

Kesimpulan: Kesimpulan yang di dapat adalah hasil variasi komposisi terbaik adalah formula II dengan jumlah tomat dan kulit buah naga yaitu 1:1 dengan tambahan gula sebanyak 50 gram. Hal ini dikarenakan stabilitas secara fisik baik yakni organoleptik warna, bau, rasa, bentuk stabil tidak memiliki banyak jamur.
\end{abstract}

Kata kunci: Tomat, Kulit Buah Naga Merah, Antioksidan, Selai lembar

\begin{abstract}
Background: In the market, more and more food products are rich in antioxidant compounds, but red dragon fruit peel (Hylocereus costaricensis cortex) which is considered as waste contains high levels of antioxidants. Tomato fruit (Lycopersicum esculentum Mill) has very strong antioxidant activity because it contains lycopene which is the main pigment in tomatoes.

Purpose: This study aims to make a combination sheet jam preparation of tomatoes and dragon fruit peel as an antioxidant-rich supplement that is easy to safe, practical and healthy for public consumption.

Methods: The research method used is action research using research instruments in the form of an organoleptic test sheet and a preference test. Preparations made with the composition ratio of tomatoes and red dragon fruit skin, each formula is 100 grams of tomatoes :100 grams of red dragon fruit skin and a variety of sweeteners for $F$ I as much as 40 grams, for F II as much as 50 grams and sweetener for F III as much as 60 grams.

Results: The results of the organoleptic test at room temperature $\left(15-30^{\circ} \mathrm{C}\right)$ showed that there was a change from day 6 to day 21, while the organoleptic test results at cold
\end{abstract}


temperatures $\left( \pm 4^{\circ} \mathrm{C}\right)$ had no change from day 1 . Until the 21st day, the result of the favorite sheet jam test was formula 2, which was $86.6 \%$.

Conclusion: The conclusion that can be obtained is the result of the best composition variation is formula II with the number of tomatoes and dragon fruit skin is 1: 1 with added sugar as much as 50 grams. This is because the physical stability is good, namely organoleptic color, smell, taste, stable form does not have many fungi.

Keywords: Tomato, Red Dragon Fruit Skin, Antioxidant, Jam Slice

\section{PENDAHULUAN}

Di pasaran semakin banyak beredar produk bahan pangan yang kaya akan senyawa antioksidan. Kandungan antioksidan pada bahan pangan dapat meredam radikal bebas sebelum menyerang sel yang memicu pertumbuhan sel kanker dan berbagai penyakit radikal bebas lainnya [1].

Menurut penelitian yang dilakukan [2] buah tomat (Lycopersicum esculentum Mill) memiliki aktivitas antioksidan yang sangat kuat karena mangandung likopen yang merupakan pigmen utama pada tomat. Sehingga tomat juga memiliki kandungan yang berpotensi sebagai antioksidan. Selain buah tomat, kulit buah naga merah (Hylocereus costaricensis cortex) juga mengandung antioksidan yang dapat dijadikan obat herbal alami dalam bidang farmakologi [3]. Menurut penelitian [4] keunggulan dari kulit buah naga yaitu kaya polifenol dan merupakan sumber antioksidan.

Awal mulanya selai dikemas dalam bentuk jar (toples). Namun kini selai telah dimodifikasi dalam bentuk lembaran. Bentuknya seperti keju lembar (chesee slice) karena lebih praktis [5]. [6] menyatakan bahwa selai lembaran berkualitas baik memiliki karakteristik tidak lengket dengan kemasan, serta tidak cair. Selai lembaran menjadi salah satu produk yang dapat dikembangkan di Indonesia karena dapat menyesuaikan pola hidup masyarakat modern yang membutuhkan waktu singkat dalam bekerja khususnya dalam proses penyajian produk pangan.

Kulit buah naga digunakan karena belum sepenuhnya dimanfaatkan dan hanya dibuang sebagai sampah sehingga perlu adanya upaya pemanfaatan limbah kulit buah naga merah. Kandungan antosianin dalam kulit buah naga dapat bermanfaat sebagai pewarna alami. Selain penambahan kulit buah naga sebagai pewarna alami, peneliti juga menambahkan kayu manis dalam produk pangan ini. Kayu manis selama ini berpotensi sebagai antimikroba yang dapat dimanfaatkan sebagai bahan pengawet pada produk makanan. Bubuk kayu manis dapat mengawetkan roti manis selama 7 hari [7]. Penelitian sebelumnya tentang pembuatan selai lembar pernah dilakukkan dengan memanfaatkan kulit semangka dan terong belanda oleh [8] penelitian tersebut bertujuan untuk memperoleh formulasi pencampuran kulit semangka dan terong belanda yang tepat terhadap kualitas kimia dan sensori selai lembaran. Oleh karena itu peneliti memilih tomat dan kulit buah naga merah sebagai bahan untuk pembuatan selai lembar kaya antioksidan dengan penambahan bubuk kayu manis sebagai pengawet pada produk pangan.

\section{METODE PENELITIAN}

Penelitian ini menggunakan metode penelitian tindakan (action research). Penelitian tindakan mengacu pada proses yang berganti secara terus menerus antara penyelidikan dan tindakan antara praktik dan berfikit inovatif [9].

\section{HASIL PENELITIAN}

Hasil pembuatan selai lembar tomat dan kulit buah naga merah yang dapat digunakan sebagai antioksidan. Proses pembuatan selai lembar ini dilakukan di laboratorium galenika dan laboratorium dietetik STIKes Holistik Purwakarta yang berada di JL. Kapten Halim KM.9, Salam 
Mulya, Pondok Salam, Kabupaten Purwakarta. Penelitian dilaksanakan pada bulan Juli sampai dengan Agustus 2020 selama 3 minggu. Tomat yang digunakan adalah tomat sayur (Lycopersicon esculentum Mill) dan kulit Buah naga merah diperoleh langsung dari pasar baru Karawang. Bagian yang digunakan dari buah naga merah adalah kulitnya sedangkan bagian tomat yang digunakan adalah kulit dan dagingnya.

Sediaan selai lembar tomat dan kulit buah naga merah yang telah selesai dilakukan pengujian stabilitas sediaan secara organoleptik dengan mengamati warna, aroma, dan rasa yang dilakukan selama 3 minggu dan disimpan pada suhu ruang $(15-30 \mathrm{oC})$ dan suhu dingin $( \pm 4 \mathrm{oC})$. Adapun uji kesukaan pada penelitian ini.

\section{Hasil Uji organoleptik}

Sediaan selai lembar tomat dan kulit buah naga merah yang telah selesai dilakukan pengujian stabilitas sediaan secara organoleptik dengan mengamati warna, aroma, dan rasa selama 3 minggu dengan pengamatan setiap 3 hari sekali disimpan pada suhu ruang $\left(15-30^{\circ} \mathrm{C}\right)$ dan suhu dingin $\left( \pm 4^{\circ} \mathrm{C}\right)$. Kemudian hasil dicatat dalam bentuk tabel.

Tabel 1. Hasil Uji organoleptik Suhu Ruang (15-300)

\begin{tabular}{|c|c|c|c|c|c|c|c|c|c|}
\hline Sampel & Pengamatan & 1 & 3 & 6 & $\begin{array}{c}\text { Hari Ke- } \\
9\end{array}$ & 12 & 15 & 18 & 21 \\
\hline \multirow{5}{*}{$\mathrm{F} 1$} & Warna & Merah & Merah & Merah & Merah & Merah & $\begin{array}{c}\text { Merah } \\
\text { tua }\end{array}$ & $\begin{array}{c}\text { Merah } \\
\text { tua }\end{array}$ & $\begin{array}{c}\text { Merah } \\
\text { tua }\end{array}$ \\
\hline & Bau & $\begin{array}{l}\text { Khas } \\
\text { tomat }\end{array}$ & $\begin{array}{l}\text { Khas } \\
\text { tomat }\end{array}$ & $\begin{array}{l}\text { Khas } \\
\text { tomat }\end{array}$ & $\begin{array}{l}\text { Khas } \\
\text { tomat }\end{array}$ & $\begin{array}{c}\text { Khas } \\
\text { tomat } \\
\text { memudar }\end{array}$ & $\begin{array}{c}\text { Khas } \\
\text { tomat } \\
\text { memudar }\end{array}$ & $\begin{array}{c}\text { Khas } \\
\text { tomat } \\
\text { memudar }\end{array}$ & $\begin{array}{c}\text { Khas } \\
\text { tomat } \\
\text { memudar }\end{array}$ \\
\hline & Rasa & $\begin{array}{l}\text { Agak } \\
\text { manis }\end{array}$ & $\begin{array}{l}\text { Agak } \\
\text { manis }\end{array}$ & $\begin{array}{l}\text { Agak } \\
\text { manis }\end{array}$ & $\begin{array}{l}\text { Agak } \\
\text { pahit }\end{array}$ & $\begin{array}{l}\text { Agak } \\
\text { pahit }\end{array}$ & $\begin{array}{l}\text { Agak } \\
\text { pahit }\end{array}$ & $\begin{array}{l}\text { Agak } \\
\text { pahit }\end{array}$ & $\begin{array}{l}\text { Agak } \\
\text { pahit }\end{array}$ \\
\hline & Bentuk & $\begin{array}{c}\text { Agak } \\
\text { kenyal }\end{array}$ & $\begin{array}{c}\text { Agak } \\
\text { kenyal }\end{array}$ & $\begin{array}{c}\text { Agak } \\
\text { kenyal }\end{array}$ & $\begin{array}{c}\text { Agak } \\
\text { kenyal }\end{array}$ & $\begin{array}{c}\text { Agak } \\
\text { kenyal }\end{array}$ & $\begin{array}{c}\text { Agak } \\
\text { kenyal }\end{array}$ & $\begin{array}{c}\text { Agak } \\
\text { kenyal }\end{array}$ & $\begin{array}{c}\text { Agak } \\
\text { kenyal }\end{array}$ \\
\hline & Warna & Merah & Merah & Merah & Merah & Merah & $\begin{array}{c}\text { Merah } \\
\text { tua }\end{array}$ & $\begin{array}{c}\text { Merah } \\
\text { tua }\end{array}$ & $\begin{array}{c}\text { Merah } \\
\text { tua }\end{array}$ \\
\hline \multirow[t]{4}{*}{ F2 } & Bau & $\begin{array}{l}\text { Khas } \\
\text { tomat }\end{array}$ & $\begin{array}{l}\text { Khas } \\
\text { tomat }\end{array}$ & $\begin{array}{l}\text { Khas } \\
\text { tomat }\end{array}$ & $\begin{array}{l}\text { Khas } \\
\text { tomat }\end{array}$ & $\begin{array}{c}\text { Khas } \\
\text { tomat } \\
\text { memudar }\end{array}$ & $\begin{array}{c}\text { Khas } \\
\text { tomat } \\
\text { memudar }\end{array}$ & $\begin{array}{c}\text { Khas } \\
\text { tomat } \\
\text { memudar }\end{array}$ & $\begin{array}{c}\text { Khas } \\
\text { tomat } \\
\text { memudar }\end{array}$ \\
\hline & Rasa & Manis & Manis & Manis & Manis & Manis & Manis & Manis & Manis \\
\hline & Bentuk & $\begin{array}{c}\text { Agak } \\
\text { kenyal }\end{array}$ & $\begin{array}{c}\text { Agak } \\
\text { kenyal }\end{array}$ & $\begin{array}{c}\text { Agak } \\
\text { kenyal }\end{array}$ & $\begin{array}{c}\text { Agak } \\
\text { kenyal }\end{array}$ & $\begin{array}{c}\text { Agak } \\
\text { kenyal }\end{array}$ & $\begin{array}{c}\text { Agak } \\
\text { kenyal }\end{array}$ & $\begin{array}{c}\text { Agak } \\
\text { kenyal }\end{array}$ & $\begin{array}{c}\text { Agak } \\
\text { kenyal }\end{array}$ \\
\hline & Warna & Merah & Merah & Merah & Merah & $\begin{array}{c}\text { Merah } \\
\text { muda }\end{array}$ & $\begin{array}{c}\text { Merah } \\
\text { muda }\end{array}$ & $\begin{array}{c}\text { Merah } \\
\text { muda }\end{array}$ & $\begin{array}{c}\text { Merah } \\
\text { muda }\end{array}$ \\
\hline \multirow[t]{3}{*}{ F3 } & Bau & $\begin{array}{l}\text { Khas } \\
\text { tomat }\end{array}$ & $\begin{array}{c}\text { Khas } \\
\text { tomat }\end{array}$ & $\begin{array}{l}\text { Khas } \\
\text { tomat }\end{array}$ & $\begin{array}{l}\text { Khas } \\
\text { tomat }\end{array}$ & $\begin{array}{c}\text { Khas } \\
\text { tomat } \\
\text { memudar }\end{array}$ & $\begin{array}{c}\text { Khas } \\
\text { tomat } \\
\text { memudar }\end{array}$ & $\begin{array}{c}\text { Khas } \\
\text { tomat } \\
\text { memudar }\end{array}$ & $\begin{array}{c}\text { Khas } \\
\text { tomat } \\
\text { memudar }\end{array}$ \\
\hline & Rasa & $\begin{array}{l}\text { Manis } \\
\text { sekali }\end{array}$ & $\begin{array}{l}\text { Manis } \\
\text { sekali }\end{array}$ & $\begin{array}{l}\text { Manis } \\
\text { sekali }\end{array}$ & $\begin{array}{l}\text { Manis } \\
\text { sekali }\end{array}$ & $\begin{array}{l}\text { Manis } \\
\text { sekali }\end{array}$ & $\begin{array}{l}\text { Manis } \\
\text { sekali }\end{array}$ & $\begin{array}{l}\text { Manis } \\
\text { sekali }\end{array}$ & $\begin{array}{l}\text { Manis } \\
\text { sekali }\end{array}$ \\
\hline & Bentuk & $\begin{array}{c}\text { Agak } \\
\text { kenyal }\end{array}$ & $\begin{array}{c}\text { Agak } \\
\text { kenyal }\end{array}$ & $\begin{array}{c}\text { Agak } \\
\text { kenyal }\end{array}$ & $\begin{array}{c}\text { Agak } \\
\text { kenyal }\end{array}$ & $\begin{array}{c}\text { Agak } \\
\text { kenyal }\end{array}$ & $\begin{array}{c}\text { Agak } \\
\text { kenyal }\end{array}$ & $\begin{array}{c}\text { Agak } \\
\text { kenyal }\end{array}$ & $\begin{array}{c}\text { Agak } \\
\text { kenyal }\end{array}$ \\
\hline
\end{tabular}

Tabel 1 menunjukan pada 3 hari pertama, sediaan yang disimpan dalam suhu ruang menunjukan adanya perubahan berjamur pada hari ke-6. Pada hari 3 hari kedua menunjukan sediaan yang disimpan dalam suhu ruang adanya perubahan yang signifikan pada rasa, warna dan bentuk. Pada tiga hari hari ketiga sediaan yang 
disimpan dalam suhu ruang adanya warna, dan bentuk. perubahan yang signifikan pada rasa,

Tabel 2. Hasil Uji Organoleptik Pada Suhu Dingin $\left( \pm 4^{\circ} \mathrm{C}\right)$

\begin{tabular}{|c|c|c|c|c|c|c|c|c|c|}
\hline Sampel & Pengamatan & 1 & 3 & 6 & $\begin{array}{c}\text { Hari } \\
\text { Ke- } \\
9 \\
\end{array}$ & 12 & 15 & 18 & 21 \\
\hline \multirow[t]{4}{*}{ F1 } & $\begin{array}{c}\text { Warna } \\
\text { Bau }\end{array}$ & $\begin{array}{l}\text { Merah } \\
\text { Khas } \\
\text { tomat }\end{array}$ & $\begin{array}{c}\text { Merah } \\
\text { Khas } \\
\text { tomat }\end{array}$ & $\begin{array}{c}\text { Merah } \\
\text { Khas } \\
\text { tomat }\end{array}$ & $\begin{array}{c}\text { Merah } \\
\text { Khas } \\
\text { tomat }\end{array}$ & $\begin{array}{c}\text { Merah } \\
\text { Khas } \\
\text { tomat }\end{array}$ & $\begin{array}{l}\text { Merah } \\
\text { Khas } \\
\text { tomat }\end{array}$ & $\begin{array}{l}\text { Merah } \\
\text { Khas } \\
\text { tomat }\end{array}$ & $\begin{array}{c}\text { Merah } \\
\text { Khas } \\
\text { tomat }\end{array}$ \\
\hline & Rasa & $\begin{array}{l}\text { Agak } \\
\text { manis }\end{array}$ & $\begin{array}{l}\text { Agak } \\
\text { manis }\end{array}$ & $\begin{array}{c}\text { Agak } \\
\text { manis }\end{array}$ & $\begin{array}{l}\text { Agak } \\
\text { manis }\end{array}$ & $\begin{array}{l}\text { Agak } \\
\text { manis }\end{array}$ & $\begin{array}{l}\text { Agak } \\
\text { manis }\end{array}$ & $\begin{array}{l}\text { Agak } \\
\text { manis }\end{array}$ & $\begin{array}{c}\text { Agak } \\
\text { manis }\end{array}$ \\
\hline & Bentuk & Agak & Agak & Agak & Agak & Agak & Agak & Agak & Agak \\
\hline & & kenyal & kenyal & kenyal & kenyal & kenyal & kenyal & kenyal & kenyal \\
\hline \multirow[t]{3}{*}{ F2 } & $\begin{array}{c}\text { Warna } \\
\text { Bau }\end{array}$ & $\begin{array}{l}\text { Merah } \\
\text { Khas } \\
\text { tomat }\end{array}$ & $\begin{array}{c}\text { Merah } \\
\text { Khas } \\
\text { tomat }\end{array}$ & $\begin{array}{c}\text { Merah } \\
\text { Khas } \\
\text { tomat }\end{array}$ & $\begin{array}{c}\text { Merah } \\
\text { Khas } \\
\text { tomat }\end{array}$ & $\begin{array}{l}\text { Merah } \\
\text { Khas } \\
\text { tomat }\end{array}$ & $\begin{array}{l}\text { Merah } \\
\text { Khas } \\
\text { tomat }\end{array}$ & $\begin{array}{l}\text { Merah } \\
\text { Khas } \\
\text { tomat }\end{array}$ & $\begin{array}{c}\text { Merah } \\
\text { Khas } \\
\text { tomat }\end{array}$ \\
\hline & Rasa & Manis & Manis & Manis & Manis & Manis & Manis & Manis & Manis \\
\hline & Bentuk & $\begin{array}{c}\text { Agak } \\
\text { kenyal }\end{array}$ & $\begin{array}{l}\text { Agak } \\
\text { kenyal }\end{array}$ & $\begin{array}{c}\text { Agak } \\
\text { kenyal }\end{array}$ & $\begin{array}{c}\text { Agak } \\
\text { kenyal }\end{array}$ & $\begin{array}{c}\text { Agak } \\
\text { kenyal }\end{array}$ & $\begin{array}{c}\text { Agak } \\
\text { kenyal }\end{array}$ & $\begin{array}{c}\text { Agak } \\
\text { kenyal }\end{array}$ & $\begin{array}{l}\text { Agak } \\
\text { kenyal }\end{array}$ \\
\hline \multirow[t]{3}{*}{ F3 } & $\begin{array}{c}\text { Warna } \\
\text { Bau }\end{array}$ & $\begin{array}{l}\text { Merah } \\
\text { Khas } \\
\text { tomat }\end{array}$ & $\begin{array}{c}\text { Merah } \\
\text { Khas } \\
\text { tomat }\end{array}$ & $\begin{array}{c}\text { Merah } \\
\text { Khas } \\
\text { tomat }\end{array}$ & $\begin{array}{c}\text { Merah } \\
\text { Khas } \\
\text { tomat }\end{array}$ & $\begin{array}{c}\text { Merah } \\
\text { Khas } \\
\text { tomat }\end{array}$ & $\begin{array}{l}\text { Merah } \\
\text { Khas } \\
\text { tomat }\end{array}$ & $\begin{array}{l}\text { Merah } \\
\text { Khas } \\
\text { tomat }\end{array}$ & $\begin{array}{c}\text { Merah } \\
\text { Khas } \\
\text { tomat }\end{array}$ \\
\hline & Rasa & $\begin{array}{l}\text { Manis } \\
\text { sekali }\end{array}$ & $\begin{array}{l}\text { Manis } \\
\text { sekali }\end{array}$ & $\begin{array}{l}\text { Manis } \\
\text { sekali }\end{array}$ & $\begin{array}{l}\text { Manis } \\
\text { sekali }\end{array}$ & $\begin{array}{l}\text { Manis } \\
\text { sekali }\end{array}$ & $\begin{array}{l}\text { Manis } \\
\text { sekali }\end{array}$ & $\begin{array}{l}\text { Manis } \\
\text { sekali }\end{array}$ & $\begin{array}{l}\text { Manis } \\
\text { sekali }\end{array}$ \\
\hline & Bentuk & $\begin{array}{c}\text { Agak } \\
\text { kenyal }\end{array}$ & $\begin{array}{l}\text { Agak } \\
\text { kenyal }\end{array}$ & $\begin{array}{c}\text { Agak } \\
\text { kenyal }\end{array}$ & $\begin{array}{c}\text { Agak } \\
\text { kenyal }\end{array}$ & $\begin{array}{c}\text { Agak } \\
\text { kenyal }\end{array}$ & $\begin{array}{c}\text { Agak } \\
\text { kenyal }\end{array}$ & $\begin{array}{c}\text { Agak } \\
\text { kenyal }\end{array}$ & $\begin{array}{l}\text { Agak } \\
\text { kenyal }\end{array}$ \\
\hline
\end{tabular}

Pada Tabel 2 dapat dilihat dari hasil uji organoleptik sediaan yang telah dilakukan dan di amati selama 3 minggu tidak mengalami perubahan yang signifikan. Pada pengamatan hari ke-1 sampai dengan hari ke-21 ketiga sampel tersebut tidak menunjukan perubahan warna, rasa, bau dan bentuk.

\section{Hasil Uji Kesukaan}

\section{Gambar 1. Grafik Uji Kesukaan}

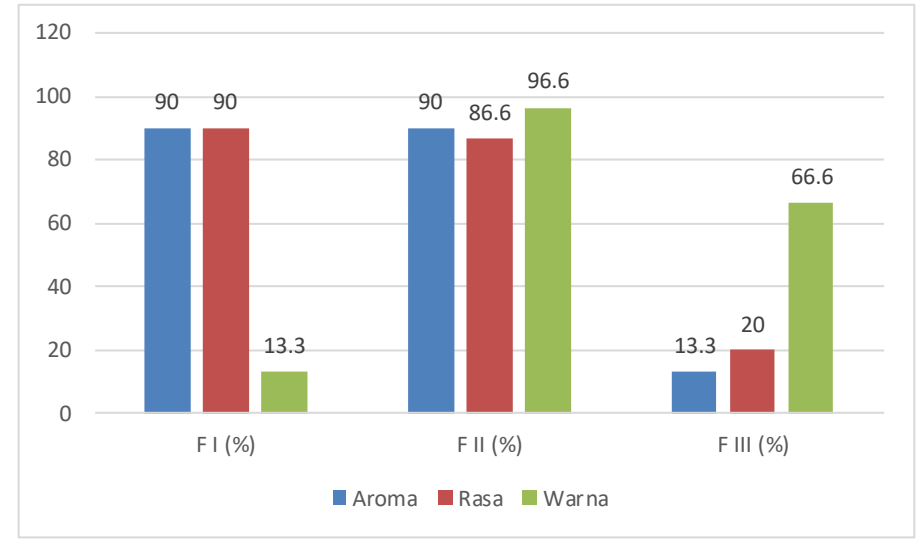

Pada hasil uji kesukaan yang tertera pada gambar 3 selai lembar dari tomat dan kulit buah naga merah yang telah di uji dan di amati 30 responden dengan kriteria jenis kelamin. Parameter pertama yaitu aroma, yang suka dengan aroma selai lembar sebanyak $90 \%$ pada formula I dan Formula II, sedangkan yang suka dengan aroma selai 
lembar sebanyak 13,3\% pada formula III. Parameter kedua yaitu rasa selai lembar sebanyak 23,3\% yang suka dengan rasa pada formula I, pada formula II sebanyak $86,6 \%$ yang suka dengan rasa selai lembar, sedangkan sebanyak $20 \%$ yang suka dengan rasa pada formula III. Parameter yang ke tiga yaitu warna, sebanyak 96,6\% suka dengan warna selai lembar pada formula I dan Formula II. sedangkan sebanyak 66,6 \% suka dengan warna selai lembar pada formula III.

\section{PEMBAHASAN}

Pada Uji Organoleptik dari ketiga sampel formulasi 1, 2, dan 3 setelah dilakukan pengujian secara organoleptik pada suhu ruang $\left(15-30^{\circ} \mathrm{C}\right)$ selama 3 minggu menunjukkan adanya perubahan yang mencolok pada tektur, warna, dan rasa yaitu pada hari ke 6 sampai hari ke-21. Sedangkan penyimpanan pada suhu dingin tetap stabil dari hari ke-1 sampai hari ke-21 hal ini sejalan dengan penelitian yang dilakukan oleh (Septi Erlinda, 2014) hasil daya simpan selai tomat selama 6 hari pada suhu dingin (kulkas) yaitu pertumbuhan jamur muncul pada hari ke enam pada yang disimpan pada suhu ruang. Selai yang disimpan pada suhu dingin tidak ditumbuhi jamur sampai hari keenam.

Menurut penelitian [11], jumlah mikrobia pada selai dipengaruhi oleh efek suhu dan lama penyimpanan. Berdasarkan penelitian yang dilakukan Okudu dan EneObong dilihat 3 dari jumlah mikrobanya, selai dapat disimpan selama 3 minggu pada suhu ruang. Setelah 3 minggu penyimpanan pada suhu ruang jumlah mikrobia yang tumbuh pada selai mencapai $35 \times 10^{3}$ dimana nilai ini sudah melebih batas yang ditetapkan oleh SNI yaitu Angka Lempeng Total maksimal $1 \times 10^{3}$. Faktor yang mempengaruhi pengeluaran air dari dalam sel adalah suhu. Suhu rendah dapat mengakibatkan pengeluaran air dari dalam sel lebih banyak.

Daya simpan di suhu dingin menyebabkan jamur terhambat untuk berkembangbiak, sedangkan daya simpan di suhu ruang menyebabkan jamur berkembangbiak dan mudah muncul dengan cepat. Suhu merupakan faktor penting untuk memperpanjang daya simpan hasil penelitian menunjukan semua selai lembar yang di simpan pada suhu dingin tidak ditumbuhi jamur, sedangkan selai lembar pada suhu ruang di tumbuhi jamur.

Pada uji kesukaan selai lembar dari tomat dan kulit buah naga merah untuk jenis pengujian dari 3 parameter yaitu aroma, rasa, dan warna dari F I, F II, FIII terhadap 30 responden Parameter pertama yaitu aroma, yang suka dengan aroma selai lembar sebanyak $90 \%$ pada formula I dan Formula II, sedangkan yang suka dengan aroma selai lembar sebanyak 13,3 \% pada formula III. Penyebab suka terhadap aroma selai lembar di karenakan aroma khas tomat yang begitu pekat. Parameter kedua yaitu rasa selai lembar sebanyak 23,3\% yang suka dengan rasa pada formula I, pada formula II sebanyak 86,6 \% yang suka dengan rasa selai lembar, sedangkan sebanyak $20 \%$ yang suka dengan rasa pada formula III. Penyebab responden yang suka pada formula II dikarenakan rasa manis pada selai lembar, dibandingkan dengan fomula III responden tidak suka karna rasanya manis pekat yaitu gula sebanyak 60 gram. Parameter yang ke tiga yaitu warna, sebanyak 96,6 \% suka dengan warna selai lembar pada formula I dan Formula II. Sedangkan sebanyak 66,6 \% suka dengan warna selai lembar pada formula III. Penyebab responden tidak suka dengan fomula III di karenakan warna formula III lebih muda di bandingkan dengan formula I dan formula II dan tidak menarik.

\section{SIMPULAN}

Hasil penelitian selai lembar tomat dan kulit buah naga merah peneliti berhasil membuat produk inovatif, aman, dan praktis dalam bentuk cemilan suplemen yang kaya antioksidan. Hasil variasi komposisi terbaik adalah formula II dengan jumlah tomat dan kulit buah naga yaitu 1:1 dengan tambahan gula sebanyak 50 gram. Hal ini dikarenakan stabilitas secara fisik baik yakni organoleptik warna, bau, rasa, bentuk stabil tidak memiliki banyak jamur. 


\section{DAFTAR PUSTAKA}

1. Yuyun Y (2016). Pemanfaatan Likopen Tomat (Lycopersicum esculentum Mill.) Dalam Sediaan Soft Candy Sebagai Suplemen Antioksidan. Journal Pharmascienc

2. Andayani, R., Lisawati, Y., Maimunah. 2008. Penentuan aktivitas antioksidan, kadar fenolat total dan likopen pada buah tomat (Solanum Lycopersicum L).

3. Cahyono, B. 2009. Buku Terlengkap Sukses Bertanam Buah Naga. Jakarta: Pustaka Mina.

4. Wu, L. C., Hsu, H. W., Chen, Y., Chiu, C. C., and Ho, Y. I., 2006, Antioxidant and Antiproliferative Activities of Red Pitaya, Food Chemistry Volume, 95: 319-327

5. Herman, T.F. 2009. Pengaruh Tingkat Pencampuran Terung Pyrus (Cyphomandra betacea Sendt) dan Rumput Laut Dalam Pembuatan Selai Lembaran. Skripsi. Teknologi Hasil Pertanian. Fakultas Teknologi Pertanian. Universitas Andalas Padang.

6. Yenrina R., N. Hamzah, dan R. Zilvia, 2009. Mutu Selai Lembaran Campuran Nenas (Ananas comusus) dengan Jonjot Labu Kuning (Cucurbita moschata). Jurnal Pendidikan dan Keluarga. Padang.

7. Kusumaningrum, Indrati dan Sutono Doddy. 2008. Kajian Mutu Kimiawi Bakso Asap dari Udang Putih (Penaeus merguiensis) Pada Berbagai Variasi Konsentrasi dan Waktu Perendaman dalam Asap Cair. Jurnal Teknologi Pertanian 4.

8. Megawati, Vonny Setiaries Johan, dan Yusmarini. 2017. Pembuatan Selai Lembaran dari Albedo Semangka dan Terong Belanda. Fakultas Pertanian, Universitas Riau.

9. Hart, E., \& Bond, M. (2000). Using action research. Using evidence in health and social care. London: Sage, 86-107.

10. Septi Erlinda Dewi. 2014. Perbandingan kadar vitamin C, Organoleptik, dan Daya Simpan Selai Buah Tomat (Lycopersicum esculentum) dan Pepaya (Carica papaya) yang di Tambahkan Gula Pasir.

11. Okudu, Helen O. Ene-Obong, Henrietta N. 2015. Evaluationn of the Effect of Storage Time and Temperature on Some Physichemical Properties of Juice and jam Developed from two Varietas of Monkey Kola (Cola parchycarpa, Cola lepidota). Africian Journal of Food Science and Thecnology Vol. 6(7) pp. 194-203. 